Western University

Scholarship@Western

Education Publications

Education Faculty

2009

\title{
Teacher Tasks for Mathematical Insight and Reorganization of What it Means to Learn Mathematics
}

George Gadanidis

The University of Western Ontario

Immaculate Kizito Namukasa

The University of Western Ontario, inamukas@uwo.ca

Follow this and additional works at: https://ir.lib.uwo.ca/edupub

Part of the Education Commons

Citation of this paper:

Gadanidis, G. \& Namukasa, I. K. (2009). Teacher tasks for mathematical insight and reorganization of what it means to learn mathematics. In B. Clarke, B. Grevholm, and R. Millman, (Eds.). Effective Tasks in Primary Mathematics Teacher Education (pp. 113-130). NY.: Springer. Available at http://www.springerlink.com/content/u42386wqr52215uj/ 


\title{
Teacher Tasks for Mathematical Insight and Reorganization of
}

\author{
What it Means to Learn Mathematics
}

\section{George Gadanidis and Immaculate Namukasa}

The mathematics-for-teachers tasks we discuss in this chapter have two qualities: (1) they offer teachers opportunities to experience the pleasure of mathematical insight; and (2) they aim to disrupt and reorganize teachers' views of what it means to do and learn mathematics. Given that many future and inservice elementary teachers fear and dislike mathematics, it is perhaps not too far-fetched to suggest that there is a need for "math therapy." We believe that a form of mathematics therapy may involve new and different experiences with mathematics. Such experiences, considered broadly to include questions or prompts for mathematical exploration, draw attention to deep mathematical ideas and offer the potential of experiencing the pleasure of significant mathematical insight. In our work with teachers we have developed and used a variety of mathematics tasks as opportunities for experiential therapy. The tasks aim to challenge some of the mathematical myths that future teachers believe to be true and are typically assumed by them in mathematics classrooms. The tasks have potential to disrupt teachers' view of mathematics, and to start the process 
for reorganizing their thinking about what mathematics is and what it means

to do and learn mathematics.

In this chapter we describe and discuss four of the mathematics tasks which involve non-routine mathematics problems that we use in our mathematics-for-teachers program. This program is offered annually to our 440 future elementary school (K-8) teachers, who generally lack confidence in mathematics and often fear and/or dislike the subject. It is also offered to inservice teachers through a series of mathematics-for-teachers courses. A student response summarizes the effects of our approach.

I felt lost at first as I struggled to remember math concepts from childhood and adolescence. I felt confused. What did a poem have to do with math? I was perplexed. Was there not only one answer to a mathematical question? I felt apprehensive. How would I discuss a mathematical concept that I did not fully understand? Then as I got into the swing of things, I felt more confident with my opinions, my answers and most importantly myself. I felt cheerful that I was experiencing math as a student and that I would hopefully be able to empathize with my future students. I felt happy that math instruction could be made to be engaging. Finally, I was giddy that I was thinking about math, actually thinking about math and not doing everything else to avoid it.

\section{Mathematics for Teachers}

It's not surprising to meet people who wear their view that "I'm not a math person" as a badge of honor. It concerns many mathematics teacher educators that this is also the case among future mathematics 
teachers. Recently, at an orientation assembly, we asked our incoming group of 440 elementary teachers how they felt about mathematics. When asked to raise their hands if they loved mathematics, 15-20 hands went up. When asked to raise their hands if they hated mathematics, a sea of hands filled the auditorium. Most elementary teachers have narrow views of what mathematics is and what it means to do mathematics (Fosnot \& Dolk, 2001; McGowen \& Davis, 2001). Given this mathematics education predicament, this not- uncommon perception of mathematics as an abhorrent subject, we suggest that there is a need for "math therapy," which involves new and different experiences with mathematics.

Our mathematics-for-teachers tasks have two qualities: (1) they offer teachers opportunities to experience the pleasure of mathematical insight; and (2) they aim to disrupt and reorganize teachers' views of what it means to do and learn mathematics.

\subsection{The Pleasure of Mathematical Insight}

The tasks are content oriented and are designed to motivate teachers to attend deeply to mathematics and to relationships among concepts. Davey (1999) argues that attention is aesthetic in nature. Whenever we bring consciousness to bear upon a topic, either individually or communally, we engage it in emotional and imaginative ways. We use 
attention to gain insight, to learn and extend ourselves, to incorporate a new thing, whether that is a new way of solving an old problem or finding new ways to express an idea. We extend our understanding, we become more complex, and this feels good (Gadanidis \& Hoogland, 2004). Dissanakye (1992) talks about an "aesthetic sensibility" that "acts as one of our primary meaning-making capacities in all domains" (p. 25). Attention is our way of gaining beauty and meaning from experience.

Our tasks, considered broadly to include questions or prompts for mathematical exploration, draw attention to deep mathematical ideas and offer the potential of experiencing the pleasure of significant mathematical insight (Gadanidis, 2004). Moments of significant insight fix the experience in one's consciousness, enriched by a strong sense of accomplishment and confidence (Burton, 1999). Insight leads to a feeling of satisfaction, a sense of great clarity, and is accompanied by a positive emotional response.

There is a sense of "authorship" of the ideas, which provides an important element of self-affirmation and confidence (Barnes, 2000). Such moments are inspiring. They are moments of deeper understanding, they have the power to transform attitudes and beliefs about what is mathematics and they inspire teachers to seek more of these moments (Liljedahl, 2002). 
To Hadamard (1996/1945), for an individual, during such moments "ideas pop up with brevity, suddenness and immediate certainty, after an incubation period, from the unconscious to the conscious" (p. 14). To Davis and Hersh (1981) such moments indicate "that something has been brought forth which is genuinely new... a new understanding for the individual; a new concept placed before the community" (p. 283). Such moments involve a shift in an entire mathematical world. In topological terms, learning, gaining insight, forming abstract concepts and observing general categories and other such radical shifts are equivalent to a cataclysmic adjustments of a space and landscape - an earthquake or an eruption. Such shifts are not simply a question of deepening or smoothening existing valleys or hills: they are about reconfiguration of the overall territory. The dynamics that might have been resetting, widening or deepening part-by-part, basin by basin at aha moments of insight, intellectual evolutions, cultural revolutions or paradigm shifts do reset all-at-once. Disrupting and reorganizing experiences does require shifts in understanding (Sumara, 2002) akin to a geographical landscape formation. Future teachers who fear mathematics may need shifts akin to therapy. Our mathematics-for-teachers program seeks to evoke changes that afford preservice teachers to move 
beyond their mathematics horizon, beyond their familiar

mathematical world through the use of content based tasks.

\subsection{Disrupting and Reorganizing Teachers'Views}

The tasks we use in our mathematics-for-teachers program help improve and deepen teachers' mathematical knowledge. However, our primary goal is not to increase teachers' mathematical content knowledge, but to offer "experiential therapy." In light of our experiential therapy goal, tasks are chosen based on their potential to disrupt teachers' view of mathematics, and to start the process for reorganizing their thinking about what mathematics is and what it means to do and learn mathematics. The tasks that we develop and use aim to challenge some of the mathematical myths that future teachers believe to be true and are typically assumed by them in mathematics classrooms, which we discuss below.

Myth 1: Mathematics is a cold science - rather than an aesthetic, human experience (Gadanidis \& Hoogland, 2004). We select tasks that promote a degree of comfort or enjoyment with doing mathematics and at the same time broaden views about mathematics. We provide opportunities for teachers to reflect on their work on the tasks by writing about what they learned and what they felt while engaged in the task. These reflections are then 
summarized and organized based on the themes that emerge and then

they are given back to the teachers to read and discuss. This provides an opportunity for teachers to see what others are thinking and feeling, to find affirmation in similar experiences of others and to rethink their own experiences in light of contrasting experiences. This also provides opportunities for discussing aesthetic qualities of the mathematics experience.

Myth 2: Mathematics is about learning procedures for getting correct answers - rather than attending to and gaining insights about the complexity of mathematical ideas (Gadanidis, 2004). An integral component of the experiential therapy is the culminating assessment, where teachers are asked to write a "math essay" on a randomly chosen task that we have worked on. Associating mathematics assessment with writing an essay shifts the focus from learning methods for answering questions to exploring more complex mathematical relationships. In writing the mathematics essay (on a maximum of two pages, in $30 \mathrm{~min}$ ), teachers choose to discuss such issues as: different strategies of solving the problem, varied mathematical connections the problem evokes, moments of insight or even frustration with the problems, extensions to the problem or related mathematical problems, and pedagogical implications. In the online discussion component of our program, teachers are 
encouraged to collaborate in preparing possible essay responses. The mathematics essay takes away the pressure of standard assessments where the focus is on being able to answer test questions, and offers teachers an opportunity to reflect on (to retell and rethink) their experience doing and learning mathematics based on one of the mathematics-for-teachers tasks.

Myth 3: A good teacher makes learning easy - rather than creating situations where students have to think hard (Jonassen, 2000). The tasks we design and use create situations where teachers have to explore complex mathematical relationships and attend to doing mathematics deeply and for extended periods of time. Teachers need to have such experiences first hand, to build up their mathematical confidence and increase their expectation of what they (and their students) are capable of accomplishing mathematically. Ginsburg (2002), who has studied young children doing mathematics, suggests that, although mathematics is "big," children's minds are bigger. He argues that "children possess greater competence and interest in mathematics than we ordinarily recognize" and we should aim to develop a curriculum for them in which they are challenged to understand big mathematical ideas and have opportunities to "achieve the fulfillment and enjoyment of their intellectual interest" (p. 7). 
Myth 4: Teaching should start with what a child already knows and understands - rather than also with what a child can imagine (Egan, 1997). The online applets that accompany the tasks often use poetry to introduce the task. Peacock (1999) suggests, poetry is screen-sized. A poem is compact enough and cohesive enough to be held in one's mind as a whole. Poetry also makes use of image and metaphor, both of which help the reader sense deeper relationships to be explored and engage the imagination (Zwicky, 2003). We also use mathematical literature as a starting point for doing mathematics, such as Lewis Carroll's (1885) A Serpent with Corners, which is discussed in Task 2. Some of the poems have also been set to music and are offered as music videos in the applets.

\section{Mathematics-for-Teachers Tasks}

In this section we share four of the mathematics-for-teachers tasks that we have designed and used. The first two tasks deal with geometry concepts and the last two tasks deal with algebra concepts.

\subsection{Task 1: I See it, it’s Invisible!}

It's amazing how exciting geometry has become for me. I never thought that as a person in my 20 s that I would be excited to look for geometric shapes in everyday life and to also try and imagine shapes in unorthodox places. This is "shaping" up to be one of the most fun university classes that I've taken. 
One of the first prompts in this task asks teachers to "Use your finger to draw an invisible circle in mid-air. Now hold it at the ends of its diameter, and flick it, making it spin. What three-dimensional figure did you cut out of space?" Prompts such as these are also in the poem that is part of the applet shown in Fig. 1. The applet also contains a music video of the poem, along with a number of annotations that offer extensions to the mathematics offered in the poem. Such applets are part of the online component of our mathematics-for-teachers program. One teacher commented, "I started to enjoy math and poems, in fact, I am trying to write one poem right now! This module made me see everything around me with a new lens!"

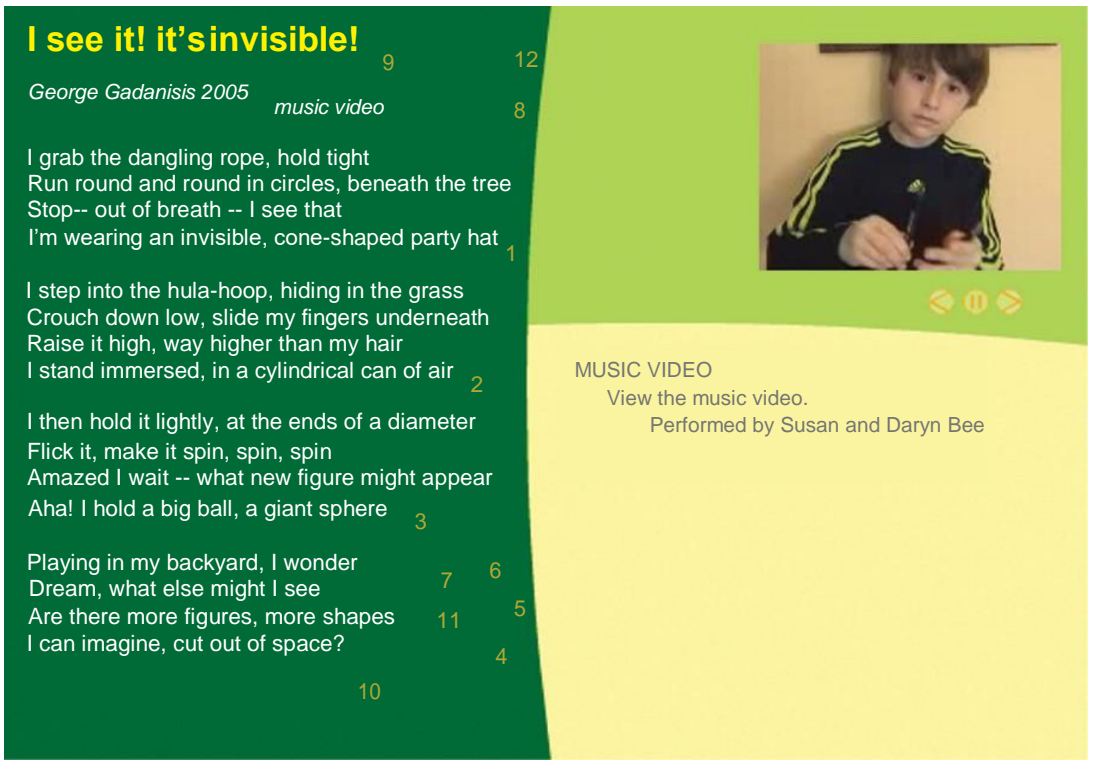

Fig. 1 "I see it, it's invisible" applet 
When we used this task in a fully online mathematics-for-teachers course, teachers used the drawing feature of our discussion board to create and post drawings that illustrated the figures they imagined being cut out of space. Figure 2 shows a curve and triangle that could be formed using one's body. "While doing my physio today I realized that by stretching into a bridge, my body makes a half-moon shape. It also helps to stretch my glutes! My physio also helped me see triangles while doing leg stretches." Figure 3 shows figures that can be created using the movement of a swing. "I used to play on a swing hanging on a big tree! But instead of swinging back and forward, I used to play twisting it so it would spin until the ropes become parallel again! I guess for few seconds I was inside a cone! It did make me feel dizzy but I liked it!" Figure 4 shows a figure skating movement to help others imagine what might be cut out of space when the triangle formed as the skater's legs twirl. Figure 5 shows an imaginary sphere formed by two cupped hands. "I was also thinking what kind of shape I could make with my hands, and after a while, I could see an invisible sphere in my hands! Yes, just imagine yourself making a snow ball!"

This task helps teachers see mathematics all around them and engage with mathematical ideas in ways that can be discussed outside of the classroom setting. As one teacher commented, 
Fig. 2 Body shapes
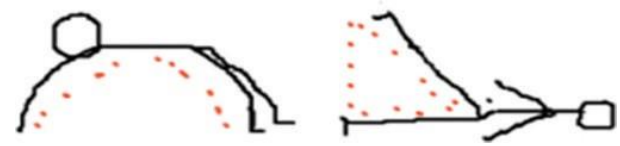

Fig. 3 A swing
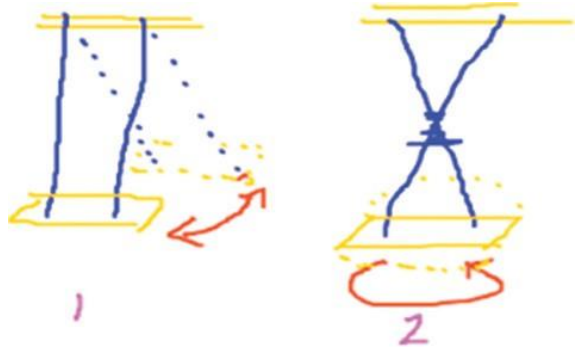

Fig. 4 Figure skating
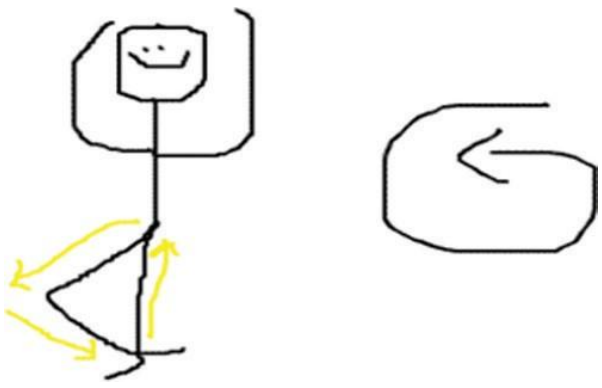

Fig. 5 A sphere

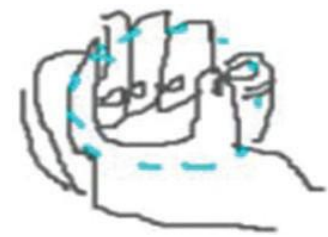

"I learned that math can be discussed with your family and friends just like you would a favorite book or new movie." Another teacher commented, "The world around us is full with geometric shapes we've never 'seen' before, just taken them as granted. I understand your feeling perfectly about the sensation of 'having new glasses' when looking around!" The task also helped teachers see a creative 
side of mathematics. "It is the first time that I have realized/felt that

math isn't just BLACK \& WHITE and can cause quite creative outcomes/discussions" (Capitals in original).

Teachers also made pedagogical connections. "I learned in this module that asking for examples from everyday life to students makes them think, discuss with each other, form opinions, learn more deeply, and remember more about that lesson. In this way math lessons can be serious and fun in the same time, and every student in the class is engaged in discussion." "I realize that it is another way of teaching math, not boring and strict how I had in school when I was younger, but funny, inspirational, imaginative; a pleasure to listen to everyone's opinions and make your own opinion about the subject. I feel that this course will remain deeply in my memory, and it will make me think twice when wanting to teach a stereotypical lesson."

\subsection{Task 2: A Serpent with Corners}

This task uses an excerpt from A Serpent with Corners (see below), from Lewis Carroll's (1885) A Tangled Tale. We selected it based on “its length (short enough given our time constraints) and due to its high mathematical potential" (Gadanidis, Simmt, Sterenberg \& Tumanov, 2004). Gadanidis et al. (2004, p. 64) note that: "As we read and discussed the story, we noticed that the flow of the story was 
interrupted at places. For example, the description of the rectangle as

being 'oblong' caused us to question whether this referred to a rectangular shape with length greater than width, or whether is also referred to elliptical shapes. It seemed to us that such an interruption, such an ambiguity, was desirable, as it caused us to imagine alternatives and to wonder about a variety of contexts for the problem stated by Balbus in the story."

"A friend of mine has a flower-garden - a very pretty one, though no great size - How big is it?" said Hugh.

“That's what you have to find out!" Balbus gaily replied. "All I tell you is that it is oblong in shape - just half a yard longer than its width - and that a gravelwalk, one yard wide, begins at one corner and runs all around it."

"Joining onto itself?" said Hugh.

"Not joining onto itself, young man. Just before doing that, it turns a corner, and runs around the garden again, alongside of the first portion, and then inside that again, winding in and in, and each lap touching the last one, till it has used up the whole of the area."

"Like a serpent with corners?" said Lambert.

"Exactly so. And if you walk the whole length of it, to the last inch, keeping in the centre of the path, it's exactly two miles and half a furlong. Now, while you find out the length and breadth of the garden, I'll see if I can think out that sea-water puzzle."

"You said it was a flower-garden?" Hugh inquired as Balbus was leaving the room. "I did," said Balbus.

"Where do the flowers grow?" said Hugh. But Balbus thought it best not to hear the question. He left the boys to their problem, and, in the silence of his own room, set himself to unravel Hugh's mechanical paradox. 
This task is also presented as an applet (shown in Fig. 6) where

variations of the problem may be explored. This usually a difficult

task for many teachers, requiring sustained attention to mathematical

processes and an exploration of multiple solution strategies. The task lends itself to algebraic and geometric solution processes, as well as a trial-and-error approach. The geometric solution typically has a significant aesthetic effect on teachers, due its simplicity and beauty. The geometric solution relates the length of the path to the area of the garden. For example, for a $5 \mathrm{~m}$ x $6 \mathrm{~m}$ garden (see Fig. 7), the area is $30 \mathrm{~m}^{2}$ and the length of the path is $30 \mathrm{~m}$, which makes sense in retrospect as the path has to travel through all of the "squares" of the garden.

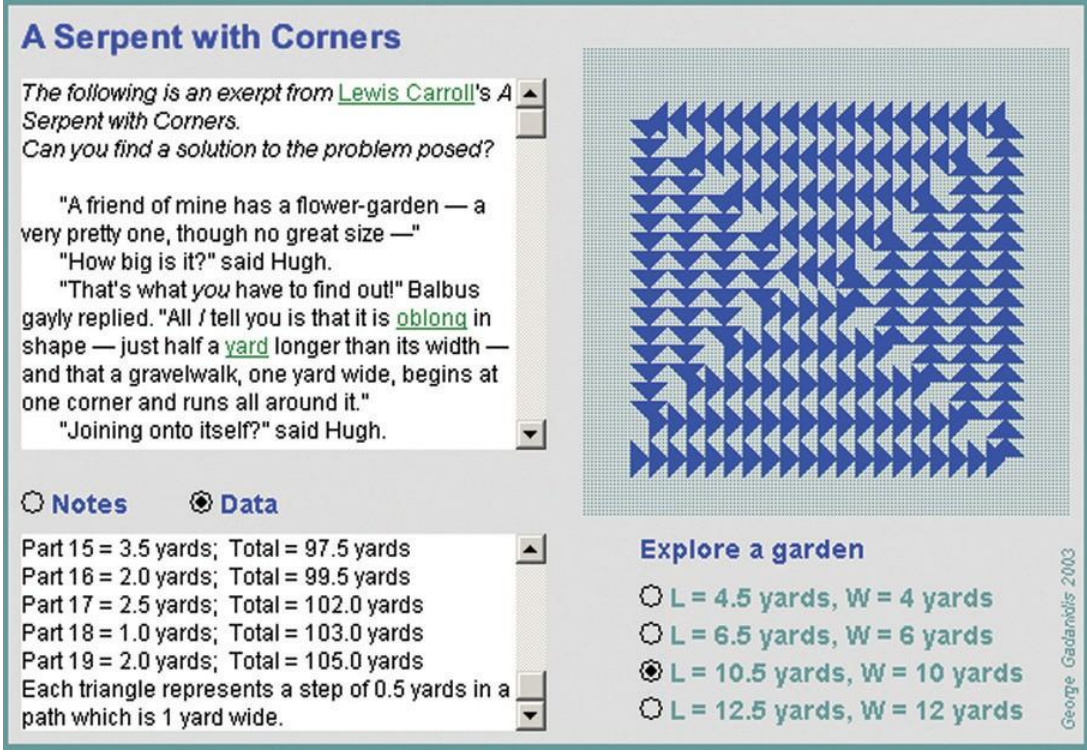

Fig. 6 "A serpent with corners" applet 


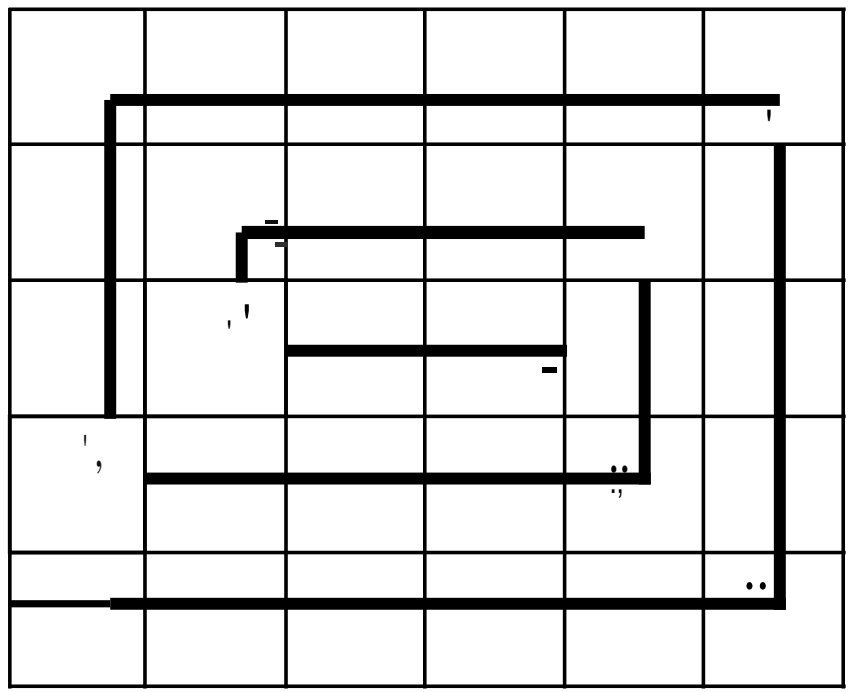

Fig. 7 The path

\subsection{Task 3: Growing Patterns}

This task has recently been developed and has been used in an inservice teacher education setting. The task starts off quite harmlessly with an exploration of growing pattern shown in Fig. 8.

The following questions are considered:

- What changes (or remains the same) as the pattern grows?

- How can we develop a rule for finding the 20 th iteration without drawing diagrams that precede it?

As teachers work on the problem, the instructor circulates and asks the question proposed by Blanton and Kaput(2003): 
- Tell me what you were thinking?

- Did you solve this a different way?

- How do you know this is true?

- Does this always work?

Blanton and Kaput (2003) suggest that "These questions not only reveal students' thinking but also prompt students to justify, explain, and build arguments-processes that lie at the heart of algebraic reasoning" (p. 73). These questions at two levels for the teachers: at the level of modelling metacognitive thinking and at the level of modelling a pedagogy they could employ in their own classroom.

The task is then extended by asking " How many square tiles are needed to the first 20 iterations?" Teachers quickly realize a few ways of finding the number of tiles needed for the 20 iterations. A few teachers focus on what changes what remains the same) in the diagram, others on what changes in the total number of tiles at each iteration and yet others at what changes from the previous iteration to the next. Those who focus on the patterns in the diagram, say that the corner tile is constant while the vertical and horizontal arms are of equal length, a length that begins at the second step and increases 
by one tile.

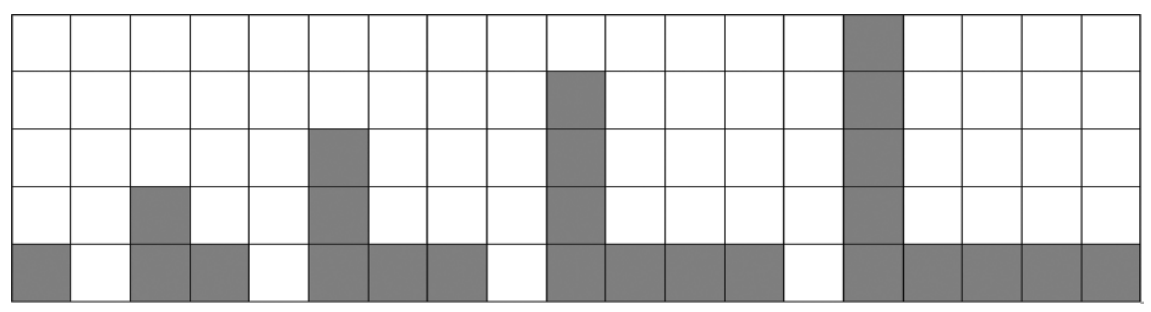

Fig. 8 A growing pattern

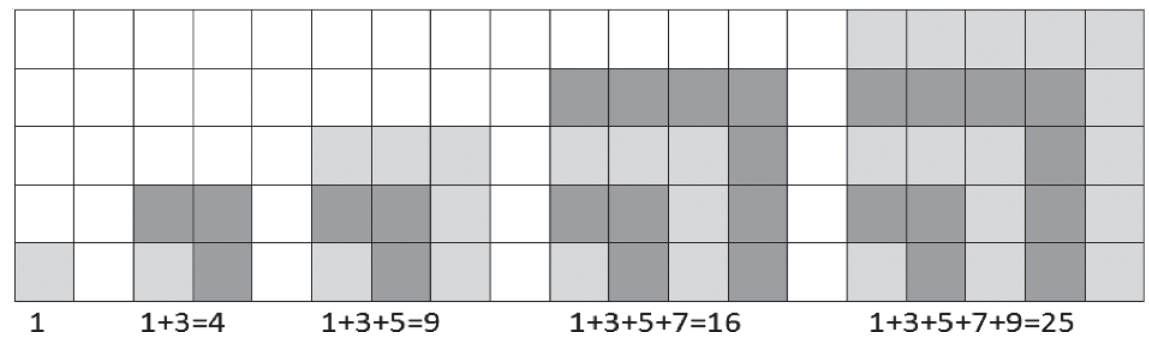

Fig. 9 Noticing that the sum of the first $N$ odd numbers is $N \times N$ or $N 2$

These teachers come up with the observation that for the 20th iteration, $1+2(20-1)$ tiles will be needed. This focus stresses what a constant and what $n-1$ in a function might mean geometrically.

When teachers focus on the changes in the iterations they soon see that the number of tiles needed for the 20 iterations is the sum of the first 20 odd numbers. In finding the sum, teachers look for patterns and try to generalize. They attend to the number patterns. They notice that odd numbers can be paired up so that $1+39=40,3+$ $37=40,5+35=40$, and so forth. This leads to solution and to a pattern that can be generalized and expressed algebraically. When 
they discover that the number of tiles needed for 20 iterations is 400 , they notice that $20^{2}=400$. This leads to further explorations where they notice that 4 tiles are needed for 2 iterations, 9 tiles for 3 iterations, 16 tiles for 4 iterations, and so forth. They discover that the sum of the first $n$ odd numbers is $n^{2}$. Using tiles of different colors they represent this visually, as shown in Fig. 9.

When we look at the pattern in Fig. 9 we experience a sense of aesthetic fit, a sense of mathematical pleasure. The image of the Ls fitting together draws our attention; it says, "look at me"; to use Heidegger' (1927-1964) phrasing, it calls us to think. We sense the pleasure of seeing the connection between the odd numbers, their geometric representations as Ls, the visual proof that the sum of the first ten odd numbers is $10^{2}$, and the general solution of finding the sum of the first $n$ odd numbers. Experiences such as these help us appreciate the beauty of mathematics and the pleasure of mathematical thinking and insight. It is such experiences that teachers need in order to develop an understanding and an appreciation of mathematics.

Teachers also begin to use the geometry of data and numbers to think about algebraic and general expressions. Their thinking is reorganized to include visual proofs. If this type of visual proof works for finding the sum of odd numbers, teachers wonder whether 
there is a visual proof for finding the sum of the natural numbers (i.e.,

$1+2+3+4+5+6+\ldots)$. Figure 10 shows a visual representation of

the sum of the first ten natural numbers. If they draw the diagonal line shown in Fig. 10, they can see that the sum (or the number of tiles needed to represent the first ten natural numbers) is a little more than the half the area of the $10 \times 10$ square. Then they consider how they might express this algebraically.

Engaging elementary school teachers with algebra is necessary, as algebra remains an Achilles heel of mathematics education. Some research indicates that the teaching and learning of algebra typically focuses on symbolic algebra over other representations (Borba \& Confrey, 1996; Kieran, 1992; Kieran \& Sfard, 1999; Nathan \& Koedinger, 2000). Consequently, though they learn to manipulate algebraic expressions, students do not seem to be able to use them as tools for meaningful mathematical communication (Kieran \& Sfard, 1999). The majority of students do not acquire any real sense of algebra and, early on in their learning of algebra, give up trying to understand algebra and resort to memorizing rules and procedures (Kieran, 1992:, Kieran \& Sfard, 1999). Kieran \& Sfard (1999) suggest that the rules of algebra may appear arbitrary to many students because "all too often they are unable to see the mathematical objects to which these rules are supposed to refer" (p. 2). Suggestions for 
providing students with meaningful experiences in algebra learning include student exploration of multiple representations of algebra concepts (Borba \& Confrey, 1996, pp. 319-320; Kieran \& Sfard, 1999, p. 3).

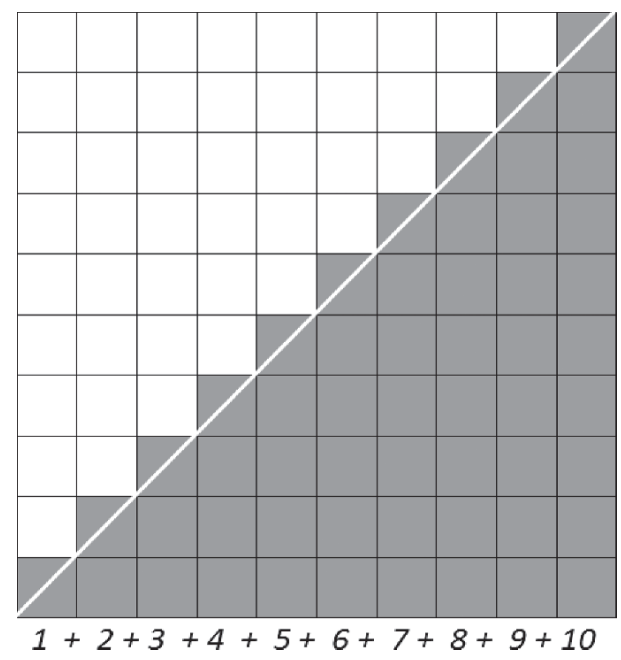

Fig. 10 A visual representation of the sum of the first ten natural numbers

It is also suggested that the traditional approach to teaching algebra, which typically starts with symbolic representation and decontextualized manipulation and later moves to visual and graphical representation and problem-based contexts, should be reversed (Borba \& Confrey, 1996, pp. 319-320). Graphs, and other visual representations, which are often treated as a mere add-on to algebra could become the foundation of algebra teaching and learning (Kieran \& Sfard, 1999, p.3). 


\subsection{Task 4: Making 10}

One of the skills that students develop in the elementary grades is that of finding missing numbers (adapted from Gadanidis (2004)). For example, they learn and practice finding missing numbers in equations such as the following:

- $-+4=15$

- $12-Y=5$

- $3 x_{--}=45$

- $\quad-\div 5=3$

Although it's important for students to practice and learn the skill of finding missing numbers in equations, the concept on its own is not a big idea in junior grade mathematics, as variables are portrayed as only representing an unknown. One way to make the learning of this skill more meaningful mathematically is to relate it to bigger ideas about equations and variables, where variables represent changing quantities.

In this task, teachers explore the equation ${ }_{--}+_{--}=10$. They roll a die to get the first number and then they calculate the second number. They write the pairs of numbers in table and in ordered pair form (see Fig. 11), and plot the ordered pairs on a grid (see Fig. 12). Then they repeat this for ${ }_{--}+_{--}=6$ and ${ }_{--}+_{--}=4$. Teachers express surprise that the ordered pairs line up (see Fig. 12). "I had the 'aha' 


$1+9=10$
$2+8=10$
$3+7=10$
$4+6=10$
$5+5=10$

Fig. 11 Ordered pairs

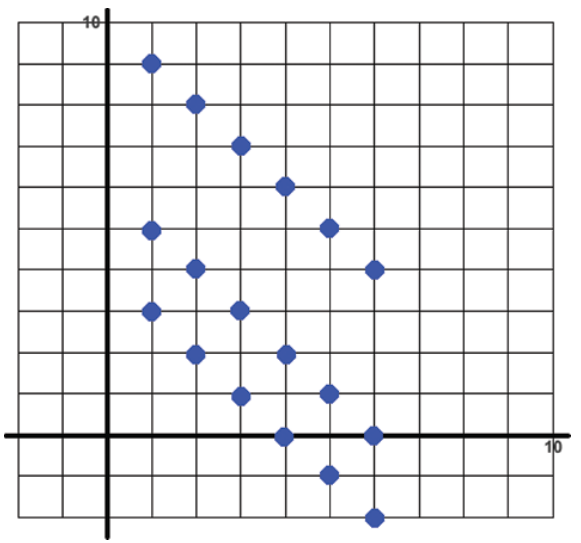

Fig. 12 Graphs

The pleasure of making 10

I still get excited when I think Of different solutions to an equation

New combinations of making 10

Fresh ways of flexing my imagination

It started in elementary schoo

I was in grade four

Doing math worksheets

When a new teacher walked in the door

We started with $+=10$

We rolled a die for the first

Then used our minds

To calculate the rest

We plotted the pairs

On a grid so fine

And discovered

They formed a line

We switched the 10

To 8 , to 4 , to 6

Forming new lines

Like parallel sticks

Our teacher then asked:

Can we change $x+y=10$ ?

Make it slope a different way?

Or swerve around a bend?

Half-way into lunch recess

While she was eating a pear

We ran to her and said:

We have an idea to share!

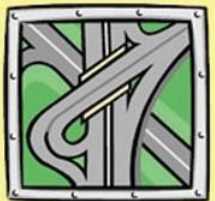

MORE LINES

Move the first slider. What is the graphical effect? Why?

Move the second slider. What is the graphical effect? Why?

Click on the + sign in the equation, which changes the sign. What is the graphical effect? Why?

Fig. 13 The pleasure of making ten 
feeling when I saw the diagonal line pattern on the graph. That was my favorite-part." Teachers also notice that the graph of ${ }_{-}{ }_{-}=4$ could be used as a visual proof of $6+-2=4$ and $5+-1=4$. That is, $(6,2)$ and $(5,1)$ line up with $(4,0),(3,1),(2,2)$ and $(1,3)$. They also explore equations whose graphs are not parallel to the ones in Fig. 12 and whose graphs were not straight lines. Such mathematical connections appear to be pleasing to teachers. "I loved the adding/graphing we did and how you could take problems and branch out ... it really makes something in my mind click."

The applet version of the task (see Fig. 13) starts with a poem that tells the story of the task from a student's point of view. It also offers opportunities to change the coefficients in linear, parabolic and hyperbolic functions and notice the dynamic effect on the graph.

This task draws teacher attention to the difference between a variable as a place holder and a variable as a changing quantity. In a typical missing number exercise, like $B+3=12$, the variable is a place holder for the missing number. In an equation like $X+Y=10$, there is a situation of co-variation, where the variable is not only expected to change, but the change in the value of one of the variables also affects the value of the second variable. 


\section{Math Therapy}

As we offer our mathematics-for-teachers program for inservice and preservice teachers, we also collect data from the learned/felt reflections done at the end of each session, the online discussions that follow sessions, and from the math essays they write at the end of the course. We conduct multi-layered, structured content analysis of the data, with the content analysis adhering to the "stage model of qualitative content analysis" defined by Berg (2004, p. 286). We do not have the space to report in detail on the method and on the findings. However, we can report some of the themes that are emerging.

\subsection{Frustration}

Many of the mathematics activities were novel experiences for the teachers. Unlike typical mathematics teaching where the teacher seeks to make learning easier by organizing classroom experiences in small, bite-sized pieces, the tasks we used sought to create opportunities for teachers to problem solve and pose new questions as well as to think in mathematical ways. However, solving non-routine mathematical problems and drawing resources from one's conceptual understanding (rather than solely from one's practiced 
procedures) in a mathematics setting, especially for people with little

experience doing so, can be a frustrating experience. Teachers

expressed a level of frustration, especially with early course

experiences, as reflected in the comments below.

I'm still frustrated by my inability to see the conclusion or the point. I can't seem to push my thinking beyond the exercise to the solution, on my own.

As they work through more tasks, teachers' frustration seems to dissipate.

My feelings of frustration are gradually turning into curiosity as I begin to think about new ways of approaching math.

\subsection{Attention and Insight}

As teachers engage with the mathematics tasks, they began to experience moments of insight. These were pleasurable moments that served as "remuneration" for the effort and attention that they gave to the problems.

... it really makes something in my mind click.

I had a lot of moments where things just popped!

When a student in our class made a discovery, our discussion reached its most enthusiastic and exciting points.

\subsection{Collaboration}

Although at times teachers were asked to think about a problem individually before attempting it as a group, the pervasive atmosphere was one of collaboration. Being able to work with others helped reduce stress with doing mathematics and exposed teachers 
to the mathematical thinking and problems solving strategies of others.

I felt really comfortable working in my group. It is easy to experiment with different things with other people versus working alone, and more ideas seem to come out.

The most important thing I learned so far is how important it is to share ideas/experience with others! In this course, I thought I would learn from ONE professor, but instead of one, I learned from many.

\subsection{Time}

Teachers were given ample class time to work on problems in a low stress atmosphere. In fact, most of the problem solving was done in class, and take-home assignments mostly consisted of course readings rather than mathematics problems.

I liked that we were asked what other methods can we come up with to test right- handedness/left etc. Then we were given time in class to go through and actually try ideas - it's been so long since I've had an experience like that in school. It was relaxing.

\subsection{The Complexity of Mathematics}

Most elementary mathematics teachers view mathematics as a subject of procedures for getting correct answers. As they worked through the mathematics-for-teachers tasks, many teachers started expressing more elaborate views of mathematics. 
Mathematics is a very complex subject that can be looked at from various angles. Infinity can be negative? What? I have never heard of a discussion of infinity or anything else "mysterious" in a math class (except this one).

Things have recently all come together for me regarding math. I see connections in and to math everywhere. Math has started to consume my thoughts.

Math is looked upon as a very dry subject, because there is the idea that there is no creativity in it, unlike English, or drama. On the contrary thanks to this course we have been shown that this is not the case.

\subsection{Teaching Mathematics}

At the beginning of the mathematics-for-teachers program, teachers expressed apprehensions about mathematics and a lack of desire to teach it. As the course progressed, preservice teachers started expressing an excitement for teaching mathematics.

It was so interesting to see how attitudes towards teaching mathematics and mathematics in general changed from the first class to the end of the term. Initially, there were numerous concerns about one's ability to teach math and fears about adequacy. However, many of these concerns often changed to feelings of excitement.

I faced my "math demons" and actually grew to enjoy a subject I thought would be my nemesis forever.

\subsection{Beliefs and Practice}

Although teachers expressed perceptions of mathematics and of teaching and learning mathematics changed significantly as the 
course progressed, these new perceptions were also accompanied with apprehensions that they would be able to put them into practice.

This class has completely shattered my understanding of math and how to teach math. It makes me feel that teaching math is going to be difficult - or at least more challenging than I previously thought. There are so many ideas I feel overwhelmed.

Teachers in the mathematics-for-teachers program overwhelmingly expressed that experiencing the course helped change their view of mathematics and of teaching and learning mathematics. In fact, the concept of doing mathematics as a therapeutic experience came from the first offering of the program. By the middle of the first course offering, students started referring to our problem solving sessions as "math therapy." However, we do not expect that a single course experience can create comprehensive or permanent changes in teachers' perceptions of mathematics and mathematics teaching. Neither can we assume that such an experience will significantly affect teachers' classroom practice; teaching is also greatly affected by accepted teaching practices in the wider school community (Buzeika, 1999; Ensor, 1998) and by conflicting priorities (Skott, 1999). However, our research indicates that such mathematics-for-teachers experiences are important starting points for change in teachers' perceptions and classroom practice. 


\section{References}

Barnes, M. (2000). Magical moments in mathematics: Insights into the process of coming to know. For the Learning of Mathematics, 20(1), 33-43.

Berg, B. L. (2004). Qualitative research methods for the social sciences. New York: Pearson.

Blanton, L. M., \& Kaput, J. J. (2003). Developing elementary teachers algebra eyes and ears. Teaching Children Mathematics, 10(2), 70-77.

Borba, M. C., \& Confrey, J. (1996). A student's construction of transformations of functions in a multiple representational environment. Educational Studies in Mathematics, 31, 319-337.

Burton, L. (1999). Why is intuition so important to mathematicians but missing from mathematics education? For the Learning of Mathematics, 19(November), 27-32.

Buzeika, A. (1999). Teachers' doubts about invented algorithms. In O. Zaslavsky (Ed.), Proceedings of the 23rd Conference of the International Group for the Psychology of Mathematics

Education (Vol. 2, pp. 161-168). Haifa, Israel: PME.

Carroll, L. (1885). A tangled tale. Accessed April 20, 2008, from, http://etext.library.adelaide. edu.au/c/carroll/lewis/tangled/tangled.html.

Davey, N. (1999). The hermeneutics of seeing. In I. Heywood \& B. 
Sandywell (Eds.), Interpreting visual culture: Explorations in

the hermeneutics of the visual (pp. 3-29). New York: Routledge.

Davis, P. J., \& Hersh, R. (1981). The mathematical experience.

Boston: Birkhäuser.

Dissanakye, E. (1992). Homo aestheticus. New York: Free Press.

Egan, K. (1997). The arts as the basics of education. Childhood Education, 73(6), 341-345.

Ensor, P. (1998). Teachers' beliefs and the problem of the social. In
A. Olivier \& K. Newstead (Eds.), Proceedings of the 22nd
Conference of the International Group for the Psychology of
Mathematics Education (pp. 280-287). Stellenbosch, South

Africa: PME.

Fosnot, C. T., \& Dolk, M. (2001). Young mathematicians at work.

Constructing multiplication and division. Portsmouth, NH:

Heinemann.

Gadanidis, G. (2004). The pleasure of attention and insight.

Mathematics Teaching, 186(1), 10-13.

Gadanidis, G., \& Hoogland, C. (2004). Mathematics as story. In G.

Gadanidis, C. Hoogland, \&B. Sedig (Eds.), Mathematics as

story: Mathematics through the lenses of art \& technology

(pp. 128-135). Toronto, ON: Fields Institute for Research in Mathematical

Sciences. 
Gadanidis, G., Simmt, E., Sterenberg, G., \& Tumanov, V. (2004). Mathematics

as story. In G. Gadanidis, C. Hoogland, \& C. Sedig (Eds.), Mathematics as story: Mathematics through the lenses of art \& technology (pp. 62-65).

Toronto, ON: Fields Institute for Research in Mathematical Sciences.

Ginsburg, H. G. (2002). Little children, big mathematics: Learning and teaching in the pre-school. Proceedings of the 26th Conference of the International Group for the Psychology of Mathematics Education (Vol. 1, pp. 3-14).University of East Anglia.

Hadamard, J. (1996/1945). The mathematician's mind: The psychology of invention in the mathematical field. Princeton, NJ: Princeton University.

Heidegger, M. (1927-1964). Basic writings. In D. F. Krell (Ed.), Revised \& expanded edition. New York: Harper Collins.

Jonassen, D. H. (2000). Computers as mindtools for schools. Engaging critical thinking (2nd ed.). Upper Saddle River, NJ: Merrill/Prentice-Hall.

Kieran, C. (1992). The learning and teaching of school algebra. In D.

A. Grouws (Ed.), Handbook of research on mathematics teaching and learning (pp. 390-419). New York: MacMillan.

Kieran, C., \& Sfard, A. (1999). Seeing through symbols: The case of equivalent expressions. Focus on Learning Problems in Mathematics, 21(1), 1-17. 
Liljedahl, P. (2002). The 'aha moment: Students' insight into the

learning of mathematics. Proceedings of the 24th Annual

Meeting of the North American Chapter of the International

Group for the Psychology of Mathematics Education (pp. 887896). University of Georgia.

McGowen, M. A., \& Davis, G. E. (2001). What mathematics knowledge do preservice elementary teachers value and remember? In R. Speiser, C. A. Maher, \& C. N. Walter (Eds.), Proceedings of the 23rd Annual Meeting, North American Chapter of International Group for the Psychology of Mathematics Education (pp. 875-884). Snowbird, Utah.

Nathan, M. J., \& Koedinger, K. R. (2000). An investigation of teachers' beliefs of students' algebra development. Cognition and Instruction 18(2), 209-237.

Peacock, M. (1999). How to read a poem . . . and start a poetry circle. Toronto, ON: McClelland and Stewart.

Skott, J. (1999). The multiple motives of teaching activity and the role of the teacher's school mathematical images. In O. Zaslavsky (Ed.), Proceedings of the 23rd Conference of the International Group for the Psychology of Mathematics Education (Vol. 4, pp. 209-216). Haifa, Israel: PME.

Sumara, D. (2002). Why reading literature in schools still matters: 
Imagination, interpretation, insight. Mahwah, NJ: L. Erlbaum.

Zwicky, J. (2003). Wisdom \& metaphor. Kentville, Nova Scotia: Gaspereau Press.

\section{Authors}

G. Gadanidis

Associate Professor, Faculty of Education, The University of Western Ontario, Canada

I. Namukasa

Assistant Professor, Faculty of Education, University of Western Ontario, Canada 